\title{
Short communication: Risk factors identified at arrival associated with average daily gain at a grain-fed veal facility: A prospective single cohort study
}

\author{
K. Scott, D. F. Kelton, (ㄱ) T. F. Duffield, (๑) and D. L. Renaud* ${ }^{*}$ \\ Department of Population Medicine, University of Guelph, Guelph, ON, Canada N1G 2W1
}

\begin{abstract}
The primary objective of this prospective cohort study was to identify factors evaluated upon arrival at a grain-fed veal facility that were associated with increased growth. A secondary objective was to determine if the factors associated with average daily gain (ADG) varied between the pre- and postweaning periods. Calves were visually assessed and scored using a standardized health scoring system immediately upon arrival. They were also weighed and vaccinated, and had blood drawn from their jugular vein to determine their serum total protein level. Weights were taken on $\mathrm{d}$ 49 and 78 after arrival and were used to calculate ADG. Three mixed linear regression models were created to determine factors associated with ADG from 0 to 49 $\mathrm{d}$ after arrival, 0 to $78 \mathrm{~d}$ after arrival, and 49 to $78 \mathrm{~d}$ after arrival. A total of 998 calves were evaluated and weighed upon arrival; 636 and 915 of those calves were weighed at d 49 and d 78, respectively. Mean ADG were $610 \mathrm{~g} / \mathrm{d}$ from 0 to $49 \mathrm{~d}$ after arrival, $860 \mathrm{~g} / \mathrm{d}$ from 0 to $78 \mathrm{~d}$ after arrival, and $1,240 \mathrm{~g} / \mathrm{d}$ from 49 to $78 \mathrm{~d}$ after arrival. In the model evaluating growth from 0 to $49 \mathrm{~d}$, calves arriving at the facility with a higher body mass index (BMI) gained more weight per day than calves that arrived with a lower BMI. If calves arrived in the spring, they gained $201 \mathrm{~g} / \mathrm{d}$ more than calves that arrived in the winter. For the period following weaning (d 49 to 78), BMI was also associated with growth. For every additional $1 \mathrm{~g} / \mathrm{cm}^{2}$ increase in BMI at arrival, calves gained an additional $1.55 \mathrm{~g} / \mathrm{d}$ from d 49 to 78 . Growth from arrival to d 78 was affected solely by BMI. For every $1 \mathrm{~g} / \mathrm{cm}^{2}$ increase in $\mathrm{BMI}$ at arrival, calves gained $1.23 \mathrm{~g} / \mathrm{d}$ more during the entire observation period. Body mass index and season at arrival affected growth through the initial period at a grain-fed veal facility. Producers should consider
\end{abstract}

Received July 5, 2019.

Accepted September 3, 2019.

*Corresponding author: renaudd@uoguelph.ca these factors, especially BMI, when purchasing calves to maximize the calves' growth potential.

Key words: health status on arrival, male dairy calf, growth

\section{Short Communication}

The profitability of a veal farm relies heavily on the growth of the calves; higher growth efficiency leads to higher revenue for the producer. Hence, it is imperative to have an understanding of factors that influence growth to maximize profitability. It is clear that diseases that occur during the growing period have a significant effect on growth. Pardon et al. (2013) demonstrated calves with bovine respiratory disease or diarrhea at a veal calf facility had 8.2 - or $9.2-\mathrm{kg}$ reductions in hot carcass weight, respectively. Similar effects have also been demonstrated in dairy heifer calves: diarrhea, bovine respiratory disease, and umbilical infections lead to reduced calf growth (Virtala et al., 1996; Windeyer et al., 2014).

Identifying calves that will be at a growth disadvantage upon arrival at a veal facility may allow for the implementation of strategies to minimize the effect on ADG. Previous studies have shown that many calves arrive at veal facilities with identifiable health abnormalities that can influence their growth (Renaud et al., 2018a). Dehydration score, BW at arrival, and season at arrival have been associated with reduced ADG (Renaud et al., 2018a). However, that study was performed at a single milk-fed veal facility. Additional research is required to confirm these study results and explore additional risk factors that could influence growth. The objectives of this cohort study were to describe the health status of calves upon arrival at a grain-fed veal facility and to associate characteristics of the arriving calf with ADG. A secondary objective was to determine whether the factors associated with ADG varied between the pre- and postweaning periods.

We collected data from a grain-fed veal facility in Southwestern Ontario, Canada, from January to De- 
cember 2017. We selected this facility based on an established relationship with, and proximity to, the University of Guelph. The study was conducted in accordance with University of Guelph Animal Care Committee requirements (Animal Use Protocol: \#3695).

Calves were transported to this facility from local dairy farms or from auction. Upon arrival at the facility, a single graduate student, who had been trained by a veterinarian, examined all calves using a standardized health scoring system. Facility staff weighed the calves using a Tru-Test digital weigh scale. All of the animals were vaccinated with an intranasal bacterin (Once PMH IN; Merck Animal Health, Kirkland, QC) and an intranasal viral vaccine (Bovilis IN; Merck Animal Health). Calves were fed a milk replacer diet for $49 \mathrm{~d}$ before transitioning to a grain-based diet after weaning. All milk replacers contained decoquinate $(30 \mathrm{mg} / \mathrm{kg})$ and were formulated to contain $26 \% \mathrm{CP}, 17 \%$ fat, $2.4 \%$ Lys, $0.8 \%$ Met, and $1.6 \%$ Thr. Milk replacers were bucketfed at a daily feeding rate of $520 \mathrm{~g}$ for wk 1 to $2,650 \mathrm{~g}$ for wk 3, and $900 \mathrm{~g}$ for wk 4 to 5 in a total of 4,5 , and $6 \mathrm{~L}$ of solution, respectively; feedings were split evenly between morning and evening. All calves were weaned over 2 -wk period by feeding $450 \mathrm{~g}$ of milk replacer once daily in wk 6 and $450 \mathrm{~g}$ once every third feeding in wk 7. Calves were offered texturized calf starter (18\% CP) upon arrival until wk 3 and transitioned to a corn and pellet ration with $2 \%$ straw $(18.1 \% \mathrm{CP})$. In a subset of rooms, an oral antimicrobial (neomycin, NeoMed; Bimeda Inc., Terrace, IL) was provided with the milk. The use of the oral antimicrobial varied depending on whether a feed additive trial was being conducted and was not based on the health status of the arriving calves.

Calves were housed individually for the first $21 \mathrm{~d}$ after arrival in stalls with slatted rubber flooring. Following the initial 21-d acclimatization period, the partitions were removed and calves were housed in groups of 5. After $11 \mathrm{wk}$, the calves were transported to a larger group-housing facility, where they were housed for an additional $20 \mathrm{wk}$, until slaughter. Data were not captured beyond $11 \mathrm{wk}$, because the larger group-housing facility did not have reliable records.

The facility staff weighed the calves at d 49 and 78 after arrival; the dates of weights were predetermined by the producer. The facility had 4 rooms, each with a capacity of up to 80 calves. Each group of calves in a room at one time was considered a "lot," and we used lots as a grouping variable in the analysis. We observed a total of 14 lots over the study period.

An iPad (Apple Inc., Cupertino, CA) with the Calf Health Scorer app (University of Wisconsin-Madison, Madison) and Qualtrics software (http://www.qualtrics .com/) was used to facilitate health scoring. Respira- tory system (nose, eye, ear, cough; McGuirk and Peek, 2014), attitude, fecal consistency (McGuirk, 2008), navel inflammation (adapted from Fecteau et al., 1997), joint swelling, and rectal temperature were evaluated using the Calf Health Scorer app. Both fecal and navel score were recategorized into 3 levels by combining the normal and slightly abnormal scores into a single group. We did this to reduce the likelihood of misclassification, because the criteria for these scores were considered ambiguous. Fecal score was categorized as follows: 1 $=$ normal semi-formed; $2=$ loose but stays on top of bedding; $3=$ watery and sifts through bedding. Navel score was also categorized using 3 levels: $1=$ normal or slightly enlarged, not warm or painful; $2=$ slightly enlarged with slight pain or moisture; $3=$ enlarged with pain, heat, or malodorous discharge. Attitude score was collapsed into 2 categories, because the dull or depressed category contained only 7 animals. Collapsing these data into 2 categories represented a bright and alert calf as a 0 and a dull or depressed calf as 1 . Similarly, categories for other variables (such as rectal temperature) that did not contain sufficient animals were combined with the next closest category to allow for better data distribution. We used a Qualtrics form to record BCS (Wilson et al., 2000), the presence of a sunken flank (Bähler et al., 2012), and the level of clinical dehydration (Wilson et al., 2000). Additional information collected using the Qualtrics survey included hip height $(\mathrm{cm})$, length from withers to lumbosacral junction $(\mathrm{cm})$, and navel diameter $(\mathrm{mm}$; defined as the circumference at the base of the calf's umbilicus). Body mass index (BMI) was calculated using weight on arrival $(\mathrm{g})$ divided by the sum of the calf's length from withers to lumbosacral junction and hip height (Mei et al., 2002). This allowed for a more objective score compared with the potential subjectivity of BCS. In the statistical modeling, we used BMI was used in all models, because it had a lower Akaike's information criterion than weight at arrival, suggesting that models using BMI were better (Dohoo et al., 2010a).

Blood was collected from each calf at arrival via the jugular vein into a $10 \mathrm{~mL}$ sterile blood collection tube without an anticoagulant (BD Vacutainer; Becton, Dickinson and Co., Franklin Lakes, NJ). The blood was allowed to clot and then centrifuged at 1,500 $\times g$ for 15 min at approximately $20^{\circ} \mathrm{C}$. The serum was separated, and serum total protein was evaluated using a digital refractometer (Palm Abbe PA202x; Misco, Solon, OH).

The number of calves enrolled in this study was based on a proportion estimation sample size calculation for the required number of calves to determine a change in morbidity (Scott et al., 2019). Briefly, we based this calculation on previous literature (Pardon et al., 2015; Renaud et al., 2018a): calves identified on arrival with 
a health abnormality would have a morbidity risk of $26 \%$, and those without an abnormality would have a morbidity risk of $17 \%$. Using a $95 \%$ confidence interval and $80 \%$ power, a sample size of 916 calves was required.

We conducted statistical analyses using Stata 14 (StataCorp LP, College Station, TX). Data were imported from Microsoft Excel (Microsoft Corp., Redmond, WA) into Stata 14 and checked for completeness. We created a causal diagram to illustrate the hypothesized relationships among the dependent and independent variables and used this to guide the analyses. We generated descriptive statistics for all explanatory variables in the data set.

We built a total of 3 mixed linear regression models to evaluate factors associated with ADG, controlling for lot as a random effect. The ADG outcomes included ADG within the first $49 \mathrm{~d}$ (preweaning), ADG from 49 to $78 \mathrm{~d}$ (postweaning), and ADG over the entire $78 \mathrm{~d}$ at the facility. We calculated ADG by subtracting the calf's weight at the beginning of the observation period from its final weight at the end of the observation period ( $49 \mathrm{~d}$ or $78 \mathrm{~d}$ ) and dividing by the number of days in the period. Disease occurring during the production period was not included in the models: it was viewed as an intervening variable in the causal pathway between health status at arrival and growth performance (Dohoo et al., 2010b). A lowess smoothing curve was generated to assess the linearity of each continuous predictor variable to the outcome. If a variable failed to meet the linearity assumption, the variable was categorized. Categorized variables were split into quartiles, except for rectal temperature, which was categorized based on the presence $\left(\geq 39.5^{\circ} \mathrm{C}\right)$ or absence $\left(<39.5^{\circ} \mathrm{C}\right)$ of fever. We used Spearman and Pearson rank coefficients to determine collinearity among the variables. If the correlation coefficient between 2 variables was $\geq 0.6$, only 1 variable was retained, based on the fewest missing values, the reliability of the measurement, and biological plausibility. Explanatory variables that were unconditionally associated $(P$-value $<0.2)$ with the outcome in univariable mixed linear regression models were offered to a multivariable model through a manual backward stepwise removal process. For all variables of interest, we used $P \leq 0.05$ to assess significance. All possible interaction terms were individually tested for significance in the main effects model. A significant interaction was determined by a coefficient with $P \leq 0.05$. Only significant terms were included in the final model. If terms were not significant, we tested predictor variables for confounding based on a $20 \%$ change between the crude and adjusted coefficients. If the difference in the coefficient of a significant variable between the reduced and full model was $>20 \%$, we considered the variable to be a confounder and kept it in the model, regardless of statistical significance. Homoscedasticity of the best linear unbiased predictions (BLUPs) was assessed using standardized residuals. A scatter plot of the standardized residuals was examined to assess for patterns in the data such as fanning or coning. The normality of the residuals was assessed visually using quartile normal plots. Standardized residuals were also graphically plotted against predicted outcomes to assess for influential observations on the model. If any residual was determined to be an extreme outlier, had high leverage, or was greatly influential, it was examined for recording errors and assessed to see if removal was warranted. No variables were identified as extreme outliers or removed.

We assessed 14 lots of calves from January to December 2017. The minimum and maximum numbers of calves assessed in a lot were 40 and 82 calves, respectively. Calf age at arrival was unknown, but was suspected to be between 3 and $7 \mathrm{~d}$. All calves entering the facility were male and were not castrated. Calves were assessed throughout each season; the majority of calves were sampled in the spring $(39.8 \%$; $\mathrm{n}=397)$, followed by summer $(22.5 \%$; $\mathrm{n}=225)$, autumn $(20.5 \%$; $\mathrm{n}=205)$, and winter $(17.1 \% ; \mathrm{n}=171)$. Throughout the $78 \mathrm{~d}, 998$ calves were weighed at arrival, 636 at d 49, and 915 on d 78. Not all groups of calves were weighed at d 49, because we did not have enough labor to complete the weighing at certain time points in the trial. A total of 74 calves $(7.5 \%)$ died during the entire growing period, reflected in the reduced number of observations on d 78. Group antimicrobial therapy was administered upon arrival to $35.1 \%(\mathrm{n}=348)$ of the calves, but we found no significant association between group treatment and ADG on any level.

Descriptive statistics for the 15 explanatory variables can be found in Tables 1 and 2 for health variables measured upon arrival at the facility. Briefly, many calves arrived at the facility with health abnormalities, including $8 \%$ with a dull and depressed attitude, $13.5 \%$ with diarrhea, $19.9 \%$ with an abnormal navel, and $12.1 \%$ with dehydration. Few calves arrived with abnormal respiratory signs, but in $9.2 \%$ a single cough could be elicited after palpation of the trachea.

The mean ADG between the day of arrival and 7 wk after arrival at the facility was $610 \mathrm{~g} / \mathrm{d}$ [standard deviation (SD): $230 \mathrm{~g} / \mathrm{d}$ ]. The explanatory variables included in the main effects for the mixed linear regression model for ADG to d 49 were season at arrival, navel score, and BMI. In the final model, BMI and season at arrival were associated with growth during this period. Navel diameter was retained in the final model, because it was a confounder to BMI. Calves that entered the facility with a higher BMI gained more 
Table 1. Frequency and prevalence of categorical variables measured at arrival at a grain-fed veal facility

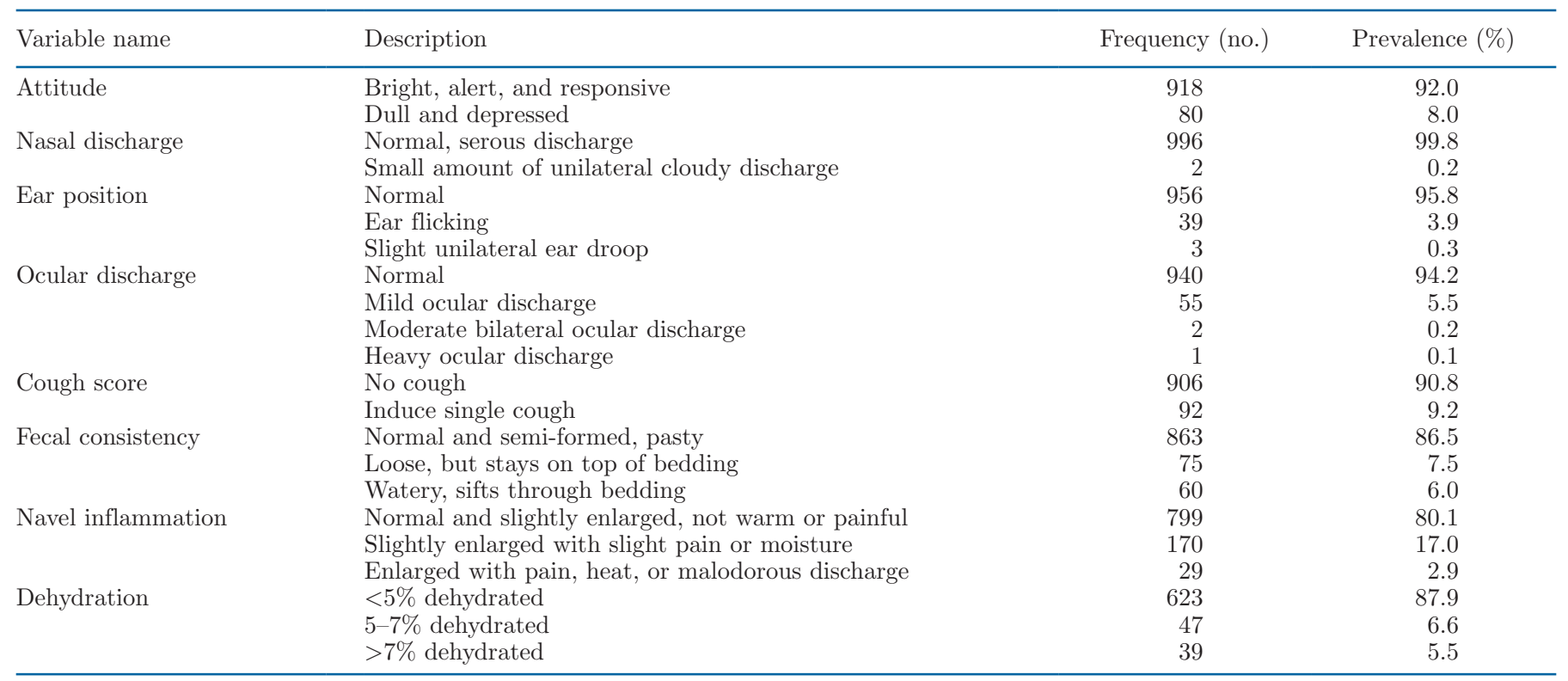

weight per day than calves that entered with a lower BMI. Calves that entered the facility during the spring (March to May) gained $201 \mathrm{~g} / \mathrm{d}$ more than calves that entered in the winter (December to February; Table $3)$. The intraclass correlation coefficient for lot of the arriving calves was 0.15 (95\% CI: 0.07 to 0.31 ).

Average daily gain from d 49 to 78 was $1,240 \mathrm{~g} / \mathrm{d}$ (SD $410 \mathrm{~g} / \mathrm{d})$. Six explanatory variables were associated with ADG in univariable analysis: season at arrival, serum total protein, navel score, eye score, and BMI. In the final model, only BMI was associated with growth in this period. For every $1 \mathrm{~g} / \mathrm{cm}^{2}$ increase in BMI, calves gained an additional $1.55 \mathrm{~g} / \mathrm{d}$ (95\% CI: $0.65-2.46 \mathrm{~g} / \mathrm{d}$; $P=0.001)$ from d 49 to 78 . For the random effect of lot, the intraclass correlation coefficient was $0.17(95 \%$ CI: $0.08-0.35)$.

Mean ADG over the entire period was $860 \mathrm{~g} / \mathrm{d}$ (SD $230 \mathrm{~g} / \mathrm{d}$ ). Navel score, rectal temperature, serum total protein, cough induced by tracheal stimulation, and BMI were associated with ADG in univariable analysis. After manual backward selection, the final model

Table 2. Mean and standard deviation (SD) of continuous variables measured at arrival at a grain-fed veal facility

\begin{tabular}{lrc}
\hline Variable name & Mean & SD \\
\hline Length $^{1}(\mathrm{~cm})$ & 46.83 & 2.86 \\
Calf hip height $(\mathrm{cm})$ & 86.69 & 3.36 \\
Navel diameter $(\mathrm{mm})$ & 25.37 & 8.99 \\
Weight on arrival $(\mathrm{kg})$ & 46.96 & 4.84 \\
Serum total protein $(\mathrm{g} / \mathrm{dL})$ & 5.76 & 0.66 \\
Body mass index $\left(\mathrm{g} / \mathrm{cm}^{2}\right)$ & 351.56 & 32.07 \\
\hline
\end{tabular}

${ }^{1}$ Length from withers to lumbar sacral junction. contained only BMI. For every $1 \mathrm{~g} / \mathrm{cm}^{2}$ increase from arrival, calves gained an additional $1.23 \mathrm{~g} / \mathrm{d}(95 \% \mathrm{CI}$ : $0.82-1.65 \mathrm{~g} / \mathrm{d} ; P<0.001)$ over the entire growing period. The intraclass correlation coefficient for lot for this model was 0.17 (95\% CI: 0.09-0.31).

The results of this study suggest that the ADG of calves at this grain-fed veal facility was associated with BMI and the season that the calves entered the facility. However, some limitations need to be considered when interpreting the findings of this study. We were unable to control for the dairy farm of origin, which has been found to be associated with growth (Renaud et al., 2018a). As well, the majority of these calves were selected by the veal producer at the dairy farm of origin. This could have led to selection bias, because calves that appeared to be healthy may have been preferentially selected over calves showing visible health concerns. Because pre-screening of calves is not practiced by most veal facilities in Canada, this could have limited the external validity of the study. An additional limitation is that we did not have access to carcass weight or live weight at slaughter. Compensatory growth could have occurred after the initial 77-d period of observation, despite the health status of the arriving calves.

In each period examined, BMI was associated with growth. This measure, based on work in humans (Mei et al., 2002), was developed to quantify the weight, height, and length of the calf, because examining weight or size alone may not give an accurate depiction of the calf's body condition. Previous work has shown that BMI and weight measured at arrival have been 
Table 3. Results of final mixed linear regression model evaluating risk factors for ADG in the first $49 \mathrm{~d}$ after arrival at a grain-fed veal facility

\begin{tabular}{llcrr}
\hline Variable & Description & $\mathrm{N}$ & Coefficient $(\mathrm{g} / \mathrm{d})$ & P-value \\
\hline Body mass index $\left(\mathrm{g} / \mathrm{cm}^{2}\right)$ & Every increase of $1 \mathrm{~g} / \mathrm{cm}^{2}$ & 915 & 0.90 & $<0.001$ \\
Season on arrival & Winter & 171 & Referent & 0.50 to 1.40 \\
& Spring & 396 & 200 & 0.01 \\
& Summer & 225 & 80 & 50 to 350 \\
Intercept & Fall & 205 & 120 & -80 to 230 \\
\hline
\end{tabular}

associated with a higher incidence of morbidity and mortality (Renaud et al., 2018b; Scott et al., 2019), so the reduced growth performance associated with a lower BMI may be a result of increased disease burden over the growing period. Because underweight calves are in a proinflammatory state after transport to a veal facility, they could be more susceptible to disease (Masmeijer et al., 2019). Because BMI and weight have consistently been shown to be associated with calf growth and health, these measures should be important targets for veal producers when selecting calves and for educating dairy producers to ensure that calves are reaching the appropriate BMI and weight before they are shipped. As mentioned by Winder et al. (2016), age, nutrition at the dairy farm of origin, and previous disease status should be investigated to determine the most important factors influencing low BW or BMI at shipment.

Calves that arrived in the winter had reduced growth compared with those arriving in the spring. The maintenance requirements of growing calves are higher in the winter because of the colder temperatures (Roland et al., 2016). Because this facility did not alter its feeding program in the winter, a lower amount of nutrients and energy for growth would have been available.

Group oral antibiotic therapy upon arrival at veal operations is a standard protocol in Canada and was previously common in Europe (Pardon et al., 2012; Jarrige et al., 2017). It was interesting that the provision of oral antimicrobials for the initial portion of the growing period was not associated with ADG in this study, similar to the findings of Pardon et al. (2015). Conversely, Rérat et al. (2012) and Berge et al. (2005) found that prophylactically treating calves for the first days after arrival at the veal facility resulted in higher ADG compared with calves that were not treated. However, contrasting results are presented by Berge et al. (2009), in which no differences in gain were observed between calves treated orally with antibiotics and those that received no treatment. Because of pressure surrounding antimicrobial use, the Canadian industry needs to explore the necessity and effectiveness of group antibiotic therapy (Jarrige et al., 2017), because it represents the majority of antimicrobial consumption in veal enter- prises (Lava et al., 2016; Jarrige et al., 2017; Bokma et al., 2019).

Observing the health status of calves on arrival at a veal facility can aid in identifying calves that could have a higher ADG. Purchasing calves with a high BMI could lead to increased ADG on the farm and less time to achieve a finished weight. However, because the prevalence of health abnormalities on arrival is high, future work should explore how to ensure proper management at the dairy farm of origin so that calves arrive in vigorous condition.

\section{ACKNOWLEDGMENTS}

The authors acknowledge the veal producer for allowing us to complete this work at their facility. We also thank Veal Farmers of Ontario (Guelph, ON, Canada) for their support of the project.

\section{REFERENCES}

Bähler, C., A. Steiner, A. Luginbühl, A. Ewy, H. Posthaus, D. Strabel, T. Kaufmann, and G. Regula. 2012. Risk factors for death and unwanted early slaughter in Swiss veal calves kept at a specific animal welfare standard. Res. Vet. Sci. 92:162-168. https://doi .org/10.1016/j.rvsc.2010.10.009.

Berge, A. C., P. Lindeque, D. A. Moore, and W. M. Sischo. 2005. A clinical trial evaluating prophylactic and therapeutic antibiotic use on health and performance of calves. J. Dairy Sci. 88:2166-2177.

Berge, A. C., D. A. Moore, T. E. Besser, and W. M. Sischo. 2009. Targeting therapy to minimize antimicrobial use in preweaned calves: Effects on health, growth, and treatment costs. J. Dairy Sci. 92:4707-4714.

Bokma, J., R. Boone, P. Deprez, and B. Pardon. 2019. Risk factors for antimicrobial use in veal calves and the association with mortality. J. Dairy Sci. 102:607-618.

Dohoo, I., W. Martin, and H. Stryhn. 2010a. Model building strategies. Pages 365-394 in Veterinary Epidemiological Research. 2nd ed. VER Inc., Charlottetown, Canada.

Dohoo, I., W. Martin, and H. Stryhn. 2010b. Confounding: Detection and control. Pages 271-322 in Veterinary Epidemiological Research. 2nd ed. VER Inc., Charlottetown, Canada.

Fecteau, G., J. Pare, D. Van Metre, B. Smith, C. Holmberg, W. Guterbock, and S. Jang. 1997. Use of a clinical sepsis score for predicting bacteremia in neonatal dairy calves on a calf rearing farm. Can. Vet. J. 38:101-104.

Jarrige, N., G. Cazeau, E. Morignat, M. Chanteperdrix, and E. Gay. 2017. Quantitative and qualitative analysis of antimicrobial usage in white veal calves in France. Prev. Vet. Med. 144:158-166.

Lava, M., G. Schüpbach-Regula, A. Steiner, and M. Meylan. 2016. Antimicrobial drug use and risk factors associated with treatment 
incidence and mortality in Swiss veal calves reared under improved welfare conditions. Prev. Vet. Med. 126:121-130.

Masmeijer, C., B. Devriendt, T. Rogge, K. van Leenen, L. De Cremer, B. Van Ranst, P. Deprez, E. Cox, and B. Pardon. 2019. Randomized field trial on the effects of body weight and short transport on stress and immune variables in 2- to 4 -week-old dairy calves. J. Vet. Intern. Med. 33:1514-1529.

McGuirk, S. 2008. Disease management of dairy calves and heifers. Vet. Clin. North Am. Food Anim. Pract. 24:139-153.

McGuirk, S. M., and S. F. Peek. 2014. Timely diagnosis of dairy calf respiratory disease using a standardized scoring system. Anim. Health Res. Rev. 15:145-147. https://doi.org/10.1017/ S1466252314000267.

Mei, Z., L. M. Grummer-Strawn, A. Pietrobelli, A. Goulding, M. I. Goran, and W. H. Dietz. 2002. Validity of body mass index compared with other body-composition screening indexes for the assessment of body fatness in children and adolescents. Am. J. Clin. Nutr. 75:978-985.

Pardon, B., J. Alliët, R. Boone, S. Roelandt, B. Valgaeren, and P. Deprez. 2015. Prediction of respiratory disease and diarrhea in veal calves based on immunoglobulin levels and the serostatus for respiratory pathogens measured at arrival. Prev. Vet. Med. 120:169-176.

Pardon, B., K. D. Bleecker, M. Hostens, J. Callens, J. Dewulf, and P. Deprez. 2012. Longitudinal study on morbidity and mortality in white veal calves in Belgium. BMC Vet. Res. 8:26.

Pardon, B., M. Hostens, L. Duchateau, J. Dewulf, K. D. Bleecker, and P. Deprez. 2013. Impact of respiratory disease, diarrhea, otitis and arthritis on mortality and carcass traits in white veal calves. BMC Vet. Res. 9:79. https://doi.org/10.1186/1746-6148-9-79.

Renaud, D. L., T. F. Duffield, S. J. LeBlanc, S. Ferguson, D. B. Haley, and D. F. Kelton. 2018b. Risk factors associated with mortality at a milk-fed veal calf facility: A prospective cohort study. J. Dairy Sci. 101:2659-2668. https://doi.org/10.3168/jds.2017-13581.

Renaud, D. L., M. W. Overton, D. F. Kelton, S. J. LeBlanc, K. C. Dhuyvetter, and T. F. Duffield. 2018a. Effect of health status evaluated at arrival on growth in milk-fed veal calves: A prospec- tive single cohort study. J. Dairy Sci. 101:10383-10390. https://doi .org $/ 10.3168 /$ jds. 2018-14960.

Rérat, M., S. Albini, V. Jaquier, and D. Hüssy. 2012. Bovine respiratory disease: Efficacy of different prophylactic treatments in veal calves and antimicrobial resistance of isolated Pasteurellaceae. Prev. Vet. Med. 103:265-273.

Roland, L., M. Drillich, D. Klein-Jöbstl, and M. Iwersen. 2016. Invited review: Influence of climatic conditions on the development, performance, and health of calves. J. Dairy Sci. 99:2438-2452. https: //doi.org/10.3168/jds.2015-9901.

Scott, K. D. F. Kelton, T. F. Duffield, and D. L. Renaud. 2019. Risk factors identified on arrival associated with morbidity and mortality at a grain-fed veal facility: A prospective, single-cohort study. J. Dairy Sci. 102:9224-9235.

Virtala, A. M., G. Mechor, Y. Gröhn, and H. Erb. 1996. The effect of calfhood diseases on growth of female dairy calves during the first 3 months of life in New York State. J. Dairy Sci. 79:1040-1049.

Wilson, L. L., J. L. Smith, D. L. Smith, D. L. Swanson, T. R. Drake, D. R. Wolfgang, and E. F. Wheeler. 2000. Characteristics of veal calves upon arrival, at 28 and 84 days, and at end of the production cycle. J. Dairy Sci. 83:843-854.

Winder, C. B., D. F. Kelton, and T. F. Duffield. 2016. Mortality risk factors for calves entering a multi-location white veal farm in Ontario, Canada. J. Dairy Sci. 99:10174-10181.

Windeyer, M. C., K. E. Leslie, S. M. Godden, D. C. Hodgins, K. D. Lissemore, and S. J. Leblanc. 2014. Factors associated with morbidity, mortality, and growth of dairy heifer calves up to 3 months of age. Prev. Vet. Med. 113:231-240. https://doi.org/10.1016/j .prevetmed.2013.10.019.

\section{ORCIDS}

D. F. Kelton () https://orcid.org/0000-0001-9606-7602

T. F. Duffield ๑ https://orcid.org/0000-0001-6035-4669

D. L. Renaud $\odot$ https://orcid.org/0000-0002-3439-3987 